\title{
O QUE É COMUNICAR E PENSAR? APORTES PARA UMA DIALÉTICA DA ALTERIDADE
}

Sérgio A. Sardi**

SÍNTESE - 0 texto, em sua estrutura argumentativa, objetiva estabelecer as condições pelas quais a linguagem deveria remeter a um contexto que ultrapassa as exigências de uma razão que identifica verdade e universalidade. As questões o que é comunicar? e o que é pensar? orientam uma perspectiva de abordagem do problema, conduzindo à consideraçōes criticas acerca da insuficiência de uma concepção da racionalidade que se funda na exciusão da alteridade.

PALAVRAS-CHAVE - Comunicar, pensar, razão, alteridade.
ABSTRACT - The text, in its argumentation structure, has the objective of establishing conditions so that language would bring $a$ context that overcomes necessities of a ration that identifies truth and universality. Te questions what is to comunicate? and what is to think? lead a perspective of the problem, conducting some critical considerations about insufficience of a conception of a rationality that has a otherity's exclusion.

KEY WORDS - to communicate, to think, reason, otherity.

\section{1- A dualidade pensar-comunicar}

Eis um fato: estamos em comunicação. ${ }^{1}$ Nossa circunstância apresenta-se, desse modo, como ponto de partida, condição e reserva de sentido à estas palavras, com as quais nos relacionamos reflexivamente ${ }^{2}$ no contexto de nossas

* Comunicação proferida por ocasião do Congresso Internacional "Dialética em Porto Alegre" PUCRS - Maio de 1998. As notas de rodapé foram acrescidas ao texto original, o qual também sofreu acréscimos.

** Doutorando em Filosofia pela Universidade de Campinas - UNICAMP - São Paulo e professor do Instituto de Filosofia e Ciências Humanas da PuCRS.

1 O contexto de uma apresentação, pelo contato direto com o público, è significativamente distinto desta "comunicação silenciosa" com o leitor, devendo ser considerado no decorrer da argumentação.

2 "A análise reflexiva acredita seguir em sentido inverso o caminho de uma constituiçăo prévia, e atingir no 'homem interior', como diz santo Agostinho, um poder constituinte que ele sempre foi. Assim a refiexão arrebata-se a si mesma e se recoloca em uma subjetividade invulnerável, para aquém do ser e do tempo. Mas isso é uma ingenuidade ou, se se preferir, uma reflexão incompleta, que perde a consciência de seu próprio começo. Eu comecei a refletir, minha reflexão é reflexão sobre um irrefletido, ela não pode ignorar-se a si mesma como acontecimento, logo que ela se manifesta como uma verdadeira criação, como uma mudança de estrutura de consciência, e cabe-lhe

\begin{tabular}{|l|l|l|l|l|l|}
\hline VERITAS & Porto Alegre & v. 43 & $\mathrm{n}^{\circ} 4$ & Dezembro 1998 & p. 1111-1120 \\
\hline
\end{tabular}


presenças. Observemos, pois, a nossa condição, enquanto a vivenciamos: o fluxo da nossa comunicação, no tempo do nosso convivio, utiliza-se de proposições as quais, ao serem proferidas e interpretadas, devem pressupor alguma identidade entre as complexas operações que cada um de nós realiza ao lhes conferir uma significação comum. Mas, ao dizer cada um, remetemo-nos a uma instância que circunscreve a alteridade imanente do comunicar, enquanto é deste indissociável. Ao revisitarmos tal domínio indizivel, dispondo-nos à dualidade do nosso gesto, transitamos entre os tênues contornos que demarcam o campo real-virtual de nossa imaginação, ${ }^{3}$ a memória que interatua continuamente com o presente, ${ }^{4}$ as nossas emoções, ${ }^{5}$ dentre outros aspectos a considerar a unidade e unicidade da

reconhecer, para aquém de suas próprias operaçōes, o mundo que é dado ao sujeito, porque o sujeito é dado a si mesmo" (MERLEAU-PONTY, M. Fenomenologia da Percepção. SP: Martins Fontes, 1994, p. 5).

3 G. BACHELARD (A Filosofia do Não. Lisboa: Ed. Presença, 1987, p. 130-131) observa como o pensamento científico opera a partir de imagens, processando, em sua história, uma relativa desconstrução das mesmas (oferece-nos, como exemplo, a história das imagens do átomo). A imagem, no entanto, teria um papel fundamental não só na formulação de uma concepção que tende a uiltrapassá-la, determinando de certo modo um ultra-objeto (como na concepção do átomo da microfísica contemporânea), como também participaria pedagogicamente das próprias possibilidades de acesso à tal concepção. Na Poética do Espaço (SP: Martins Fontes, 1993) BACHELARD irá se referir à imaginação como associada à criatividade, propondo "considerar a imaginação como uma potência maior da natureza humana" (p. 18) pois, segundo afirma: "como tese geral, pensamos que tudo o que é especificamente humano no homem é lógos. Não chegamos a meditar numa região que estaria antes da linguagem" (p. 8). H. REEVES (Imagens de Ação na Física. in A Ciência e o Imaginário. Brasília: UnB, 1994) observa que "a Fisica, como todas as outras ciências, procede por meio de imagens" sendo que, no nosso século, "as imagens de objeto são substituídas por imagens de ação". M. MLNER (Metáforas e Metamorfoses no Imaginário Científico. In A Ciência $e$ o Imaginário. Brasília: UnB, 1994), visa "indagar as modificaçōes que o pensamento cientificc traz não só para os conteúdos do imaginário, mas também para o seu regime e suas 'estruturas antropológicas'". C. CORNOLDI e R. LOGIE (Counterpoints in Perception and Mental Imagery: Introduction. In Stretching the Imagination - Representation and Transformation in Mental Imagery. New York: Oxford Univ. Press, 1996, p. 13-15) observam uma interface em diferentes niveis na relação entre linguagem e imaginação. Em PLATÃO, a utilizaçăo da analogia, enquanto procedimento metodológico, inclui a imagem no contexto da dialética ascendente (cf. SARDI, S. Dialética e Analogia na Paidéia Platônica. In Veritas, POA, v. 42, n. 4, Dez/97, p. 923-929. Vide, também, o importante estudo de MARIGNAC, A. Imagination et Dialectique - essai sur l'expression du spintuel par l'image dans les dialogues de Platon. Paris: Les Belles Lettres, 1951, onde a estrutura do problema é a mesma, embora em outro contexto conceitual: "Lié à ce grand problème des relations entre le monde intelligible et le monde sensible, il y a um problème de l'expression de l'intelligible au moyen du language sensible" (p. 11)).

4 Comp. BERGSON, H. Matière et Mémoire. Éd. du Centenaire, caps. II e III.

5 Cf. MATURANA (La realidad: objetiva o construida? Vol. I, Barcelona: Anthropos, 1995, p. 23 e Da Biologia à Psicologia. POA: Artes Miédicas, 1998, p. 98): "o que conotamos com a palavra emoção são disposiçőes corporais que especificam em cada instante o domínio de ações em que se encontra um animal (humano ou não) (...) a existência humana se realiza na linguagem e o racional a partir do emocional". A perspectiva de MATURANA, embora não dissocie emoção e razão, confere uma primazia à primeira, visto que "todo sistema racional tem um fundamento emocional" (Emociones y Lenguage en Educación y Política. Santiago: Dolmen, 1997, p. 15). O conhecer, no contexto de tal concepção, funda-se na organização autopoiética do ser vivo e, como momento do próprio dinamismo biológico, a estrutura cognitiva consiste em um modo particular de autopóiesis (cf. De Máquinas e Seres Vivos. POA: Artes Médicas, 1997, p. 106), relacionando diretamente conhecimento e ação (cf. El Árbol del Conocimiento. Ed. Universitária, cap. II). A primazia do emocionar, em MATURANA, enquanto indica uma subalternidade entre os niveis da autopóiesis (na autoprodução do ser vivo em seu fechamento estrutural) ao nivel da determinação condutual, pa- 
dinâmica individual. Atentemos, pois, à esfera inefável do gesto aparentemente simples do nosso dizer e do nosso ouvir, à dimensão dual do nosso convívio, à simultaneidade e paralelismo do movimento do para-si e do para-nós que aparecem, pois, como indicadores de um contato que se efetiva por um viés que transcende as palavras. Nesse contexto, em que paira a suspeita da insuficiência de uma lógica cuja pretensão de universalidade reduz a não-ser o indivíduo e a multidimensionalidade fenomênica de toda circunstância vivida, reavaliamos criticamente o sentido da relação entre razão e linguagem.

A perspectiva que se produz por um envolvimento com nossa con-vivência, e nos inclui intencional e integralmente na relação com a circunstância, remonta à significação $0^{6}$ de um lógos em estado nascente. Revisitamos, assim, a gênese de nossa relação com a linguagem e, por um détour, por transitarmos esse caminho

rece, no entanto, não considerar que a reflexão possa agir e retroagir sobre a emoção a partir de estruturas conceituais ou de operaçc̃es lógico-lingüisticas. Tal concepção, a nosso ver, compromete a unidade do processo cognitivo, a qual demandaria uma codeterminação entre emoção e razão. Ainda, ao considerar o fenômeno exclusivamente da perspectiva de um observador externo (vide: De Máquinas e Seres Vivos. POA: Artes Médicas, 1997, p. 193 e El Árbol del Conocimiento. Ed. Universitária, p. 92-3), circunscreve sua abordagem aos limites da "ciência". MLRLEAUPONTY (O Primado da Percepção e suas Conseqüências Filosóficas. SP: Papirus, 1990, p. 60-1) adverte, no contexto de sua argumentação, sobre a necessidade de uma dupla perspectiva ao tratarmos do conhecimento humano.

A consideração da conexão entre a linguagem e um espectro de manifestações biopsiquicas, as quais designamos genericamente por emoção, implica considerar, em nossa abordagem, que estas acompanham a percepção e a comunicação como elemento não-residual. A codeterminação entre emoçăo e razão, na complexidade de sua dinâmica, reflete uma idiossincrasia com respeito ao estar-no-mundo e designa uma produtividade caracteristica como diferencial irredutivel entre os participantes de uma comunicação. Da perspectiva de um observador que considera a si mesmo e a seu processo de observar, é insuficiente considerar a emoção de uma perspectiva estritamente comportamental, ou mesmo genericamente, sem realizar distinções qualitativas em sua interface com o conhecimento, pois desde que esteja conectada à consciência-de-si de um individuc, embora não necessariamente à esfera do autodominio, abarca uma multidimensionalidade fenomennca, da qual uma descrição mais precisa poderia nos indicar diferentes funções. Por emoção designamos, com isso, a necessária consideração da corporeidade à base dos processos cognitivos, modulando as condições peias quais um determinado ato comunicativo produz modificações na dinâmica do indivíauo. Assim, o conhecimento racional aparece intimamente conectado ao dinamismo biopsiquico, sendo cumulativo e auto-organizador na dependência mesma de tal conexão. Esboça-se, sob tal perspectiva, o sentido de uma continuidade não-linear entre sucessivas reconstruções cumulativas da significação, visto que o irrefletido - que surge à base do refietido (cf. M. PONTY, op. cit., 1990, p. 53 e 88-9) - inclui elementos não-determináveis em um processo de conhecimento que considera a integralidade do individuo em sua unidade e unicidade.

6 A resposta afirmativa à questão “ensinar e significar são a mesma coisa ou diferem em algo?", no diálogo De Magistro, de S. AGOSTINHO (In Os Pensadores, SP: Abril, 1973, p. 347), funda uma concepção de ensino a qual considera a necessária inter-relação entre subjetividade e intersubjetividade no processo comunicativo. Nesse contexto, a função das palavras é a de suscitar uma significação que se produz por um contato direto com a coisa mesma: "mas, agora, tomo-a totalmente só, segundo o seu significado; pois concordo contigo não ser possivel conversar se a mente, depois de ouvir as palavras, não se voltar para as coisas mesmas de que aquelas são sinais" (op. cit., VIII, 22, p. 342). Apesar de uma aparente insuficiência argumentativa do autor com relação ao sentido que possamos dar ao "voltar-se para as coisas mesmas", julgo pertinente o eixo central da problematização, a qual considera a dependência da linguagem a uma dimensão que ultrapassa os limites observáveis e descritiveis de um processo inter-relacional. 
de uma refiexão que repercute no silêncio, um lógos emergente, o perguntar, ${ }^{7}$ faz de sua abertura ${ }^{8}$ a força motriz de um processo dialético-dialógico. ${ }^{9} \mathrm{~A}$ formulação ${ }^{10}$ da questão o que é comunicar? abre, por uma certa mudança de nossa postura, o domínio de uma polissemia de novas interrogações, em desvelamento processual e sempre parcial da nossa vivência, ${ }^{11}$ a qual constitui o horizonte de uma reconstrução cumulativa e fenomenológica da significação. ${ }^{12} \mathrm{~A}$ questão, reflexão que atua no sentido de observar os limites e a insuficiência do próprio dizer, por uma atitude que rompe com a habitual na medida mesma em que se dis-põe à admiração $e$ ao envolvimento, aponta múltiplas perspectivas que, em seu entrecruzamento, tecem a possibilidade de uma reconciliação.

A distensão a que tende o comunicar aponta, assim, para o paradoxo da dualidade ${ }^{13}$ inerente ao gesto: ao refletirmos, cada um e conjuntamente, deparamo-

7 O perguntar compreende a especificidade de um lógos que emerge de uma certa ruptura - compreendida como continuidade não-linear - instaurada na admiração, e nos situa em movimento dialógico-dialético (Cf. SARDI, S. Da Dialética do Admirar e do Perguntar. In Veritas, POA, v. 42, n. 4, Dez/97, p. 931-936). Tal processo não esgota, no entanto, outras formas de expressão que situam a abertura e a comoção (visto que o próprio individuo é reintegrado criativamente, sendo ele mesmo modificado no decurso de tal processo), com relação à significação, no âmbito das próprias possibilidades da expressão: em G. BACHELARD, a poesia cumpre, privilegiadamente, uma função análoga, operando conexões e contrapontos em interface com o pensamento científico.

8 Poderá o movimento processual dos conceitos e da linguagem ser considerado de modo exclusivamente lógico? PLATÃO foi o primeiro a delimitar o sentido do lógos ao contexto do humano. Ao considerá-lo, também nós, neste âmbito, observamos, no entanto, sua articulação com uma fenomenologia dos processos biopsíquicos, intra e intersubjetivamente considerados.

9 Em trabalho anterior (SARDI, S. A. Diálogo e Dialética em Platão. POA: Edipucrs, 1995), observo como, no decurso do desenvolvimento da obra platônica, a dialética tende a distanciar-se do contexto intersubjetivo do diálogo para adquirir o caráter de método transcendental do conhecimento. Neste texto, dentre outros objetivos, pretendo resgatar a dimensão de uma produtividade que se gesta no entre, a qual considero de certo modo recalcada pela tradiçâo posterior do pensamento dialético.

10 E há muitas formulações possiveis à esta questão, como à toda questão filosófica, cada uma indicando uma perspectiva não-simétrica e complementar ou convergente do mesmo problema.

11 O termo vivência expressa, neste contexto, mais que um momento de um processo de conhecimento, a própria condição vivida onde a unidade e unicidade do indivíduo constituem a base da interatividade intencional que orienta todo processo cognitivo. Nesse sentido, a vivência opera retroativamente sobre as próprias condições do conhecimento, modificando e ampliando a perspectiva relacional.

12 A reconstrução cumulativa da significação, dinâmica que poderiamos pretender incluir no contexto formal de uma lógica dialética, transcende, em nossa abordagem, a esfera da discursividade, o que estabelece um primeiro sentido em considerarmos os limites de tal estrutura processual do lógos. Ainda, a consideraçäo da parcialidade fenomenológica de toda perspectiva, a qual participa do equacionamento do problema da relação entre determinação e universalidade, resulta, em nosso entender, na impossibilidade do estabelecimento não só de uma "sintese última" no contexto da dialética, mas também na insuficiência de toda determinação do sentido mesmo de "sintese" e à consideração da dialética não como lógica transcendental ou absoluta, mas lógica aplicada (sobre e última consideração, compare: BACHELARD, G. op. cit. 1987, p.100). Um processo de reconstrução cumulativa e fenomenológica da significação, como o designamos, considera o desvelamento gradual de um núcleo de significação a partir da intersecção de múltiplas perspectivas, perfazendo (e, a partir do já dado, refazendo desde o começo) os liames de uma teia na qual nós mesmos somos incluidos enquanto participamos da vida, a qual nos situa originariamente na alteridade (comp. MERLEAU-PONTY, M. op. cit., 1990, p. 47-48).

13 Dualidade considerada não como duplicidade, mas como "oscilação" bipolar no interior de uma unidade, no que consiste, propriamente, o paradoxo. O paradoxo, neste contexto, surge ao remeter a uma perspectiva aparentemente não-assimilável a partir de uma lógica constituída à base do 
nos com este espaço de um solitário e silencioso encontro com nossa voz, imagens, memória, emoções... as quais talvez possamos designar, genericamente, por "pensamentos", e participam, de algum modo, de um processo que poderíamos supor ser exclusivamente intersubjetivo. Mas sequer o juízo de uma pertença à subjetividade ou interioridade pode ser considerado de modo exclusivo. Estas palavras, que entrecruzam a aparentemente inacessivel e solitária relação que simultaneamente mantemos com nós mesmos, devem pressupor um sincronismo, uma confluência onde o pensar de cada um possa reconhecer, para si mesmo, uma conexão com o pensar de cada outro e de todos nós. Considere-se, ainda, que a tão-só presença ${ }^{14}$ do outro, como corpo e alteridade, une indissociavelmente comunicação e existência. Haveria, pois, sentido nestas palavras, se consideradas exclusivamente como exteriores ao pensar de cada um? Haveria sentido nestas palavras, se consideradas exclusivamente como imanentes ao pensar de cada um?

Demarcamos, com isso, uma outro sentido à nossa relação ao observar que tais dimensões do comunicar só nos permitem dizer cada um e dizer conjuntamente a partir de uma significação inter-relacional. Tal estrutura de significação deveria implicar, logicamente, uma alteridade imanente a cada um dos pólos - ao considerarmos o aparecer do si-mesmo como simultâneo ocultar ${ }^{15}$ e $o$ aparecer do outro no sincronismo que denota a insuficiência do dizer exclusivamente simesmo - como redução analítica de tal dualidade vertiginosa à estruturas mais simples? Ou nos remetem a conceber a própria dualidade no contexto de uma outra estrutura de significação? ${ }^{16}$

A relação entre o meu e o teu dizer e pensar o outro assim como entre o meu e o teu dizer e pensar o eu mesmo, tecendo múltiplos sentidos de uma ressonância, uma oscilação entre alteridade e identidade, resiste a ser circunscrita a uma

princípio aristotélico de não-contradição (sobre tal questão, observar os postulados de O. L. Reiser In BACHEL.ARD, op. cit., 1987, p. 109-114). Segundo MERLEAU-PONTY (op. cit., 1990, p. 52-3): "a crítica de contradição não é decisiva, se a contradiçăo reconhecida aparece como a própria condição da consciência. É nesse sentido que Platão e Kant, para falar só deles, assumiram as contradiçōes que Zenão e Hume recusaram".

14 Enquantc tão-só presença, enquanto disposto à minha atenção, em seu aparecer como corpo, o outro já participa de meu contexto de interaçōes afetando, de algum modo, um dinamismo que produz efeitos os quais, de uma perspectiva de um observador externo, traduz-se em termos comportamentais. Enquanto presença, o outro é alteridade, e somente em sua alteridade, concebida como nuança diferencial irredutivel, ele pode me comunicar. A possibilidade de uma consciência cotidianamente exercitada da alteridade, como comportamento-cognição que integra a consciência da própria unicidade - o viés da alteridade - na transcendência que faz corresponder o biós e o psíquico, funda a ética como dimensão "metafísica" de toda significação (comp. LEVINÁS, E. Totalité et Infini. La Haye: M. Nojhoff, 1971 e MERLEAU-PONTY, M. op. cit., 1994, p. 7-9 e op. cit., 1990, p. 47).

15 O que busca ultrapassar a noção de um diálogo interior (cf. PLATÃO. O Sofista, 263e e Teeteto, 189e-190a), com a qual, em trabalho anterior, busquei expressar a estrutura do dinamismo próprio da subjetividade, com base no pensamento piatônico. A noção de um diá-lógos interior pressupõe que haja uma equivalência, uma simetria entre os processos lógico-lingüisticos e os fenômenos relativos à consciência, o que equivale a uma ontologização da própria noçăo de subjetividade. Disso decorre, portanto, a própria impossibilidade de determinação de um conceito de subjetividade, embora não a de uma descrição, sempre parcial e limitada pelas próprias condições da linguagem em expressar a perspectiva de um observador que deve incluir a si mesmo e seu próprio processo de observar.

16 Inalienável da condição que me faz "ser no mundo", antes de significá-lo (Cf. MERLEAU-PONTY, M. op. cit., 1994, p. 9). 
estrutura exclusivamente lógico-formal. ${ }^{17}$ Há uma dimensão existencial irredutível no simples ato de dizer comunicar ou em dizer pensar, enquanto estou integralmente envolvido em tal gesto. Os múltiplos sentidos da correlação alteridadeidentidade, bem como sua ínsita condição existencial, sem os quais o comunicar não faria sentido, sequer o próprio pensar, nos remetem, paradoxalmente, para além da esfera da discursividade, residindo nesse movimento a condição primeira da própria discursividade.

A questão o que é comunicar? anuncia, com isso, uma gestação, ao reclamar internamente uma outra, da qual nos aproximamos em uma primeira formulação: 0 que é pensar? Mas tal questão exige de nós uma certa tomada de posição. Assim, desde que nos dispomos a uma reflexão conjunta, considerando os processos individuais no âmbito de uma correlação complexa, justifica-se exercitarmos, sem temermos uma possível perda de "objetividade", a perspectiva de observadores internos dos nossos próprios pensamentos. ${ }^{18}$ Observemos, apenas de passagem, que no intervalo de nossa reflexão põe-se, simultaneamente, em jogo, o sentido de falarmos em metalinguagem. ${ }^{19}$

\section{2-A dualidade ser-pensar}

Ao pensar em meu próprio ato de pensar sou, de súbito, inteiramente absorvido por meu próprio gesto. Enquanto penso, meu pensamento é a unidade que resulta da atividade do meu próprio pensar e, inteiramente envolvido, sou idêntico à tal atividade ${ }^{20} \mathrm{E}$ tudo aquilo ao qual eu possa dirigir meu pensar acaba por ser incluido, em última instância, nesta atividade, sendo também pensamento, existindo, para mim, antes de mais nada, como tal.

17 Mesmo se considerarmos uma lógica não-aristotélica.

18 O cogito cartesiano, para citar este único exemplo, é impensável fora de tal perspectiva (comp. MERLEAU-PONTY, M. op. cit., 1994, p. 4).

19 Haverá, pois, um modo outro de estar na linguagem, isto é, de "dizê-la" e de "ouvi-la", a partir de um contexto que a transcende? Será possivel exercer uma meta-linguagem especial que, situandonos na linguagem, estabeleça a significação desta na possibilidade de suscitar e tornar disponível algo que, por sua natureza ou pela natureza da razão, deva estar além das estruturas reguladoras de um pensamento que se articula como universalidade impessoal?

20 Comp. FICHTE, J. G. O Princípio da Doutrina-da-Ciência In Os Pensadores, SP: Abril, 1973: "O conceito ou o pensamento do eu consiste no agir sobre si do próprio eu; e, inversamente, um tal agir sobre si mesmo dá o pensamento do eu, e pura e simpiesmente nenhum outro pensamento" (I, 523); "há uma consciência em que o subjetivo e o objetivo absolutamente não se separam, e são absolutamente um e o mesmo" (II, 527); "uma consciência em que o subjetivo e o objetivo estão imediatamente unificados. A consciência de nosso próprio pensar é essa consciência" (II, 528); "toda consciência possivel, como objeto de um sujeito, pressupõe uma consciência imediata ein que o subjetivo e o objetivo sejam pura e simplesmente um; sem isso, a consciência é pura e simplesmente inconcebivel” (II, 528). Mas, concebida como pura atividade, a consciência não se deixa explicar, pois recai em petição de princípio (cf. II, 526). Com isso, FICHTE necessitará estabelecer a condição de uma determinidade do pensar (pois, como pura atividade, o pensar prescindiria de um ponto fixo, como principio da determinaçāo do conceito), a qual consiste no repouso, pressuposto pela própria atividade do pensar (cf. II, 531-533). Assim, "o conceito, onde quer que apareça, nada mais é do que a atividade do próprio intuir, não captada como agilidade, mas como repouso e determinidade; e é isso que ocorre também com o conceito do eu. A atividade que retorna a si, captada como fixa e persistente - pela qual desde logo ambos, eu, como ativo, e eu, como objeto de minha atividade, coincidem - é o conceito do eu" (III, 533). FICHTE permanece, durante toda a sua reflexão, no campo do idealismo transcendental (cf. II, 530). 
Se, neste momento, tomo uma xícara com café nas mãos, observando sua textura, forma, odor, temperatura e sabor, tal percepção, ${ }^{21}$ enquanto sou eu que a efetivo e, assim, a penso, é, também ela, pensamento. Todo o universo do meu conhecimento, todo o espaço de minhas relações, o que quero significar ao dizer que estou situado no mundo, ${ }^{22}$ o que denominamos por consciência, ${ }^{23}$ tudo isso é, para mim, de uma perspectiva exclusiva do pensar, antes de mais nada, pensamento. Ao pensar em meu corpo, o seu aparecer revela a mim a própria atividade que o faz ser para mim, confundindo-se, nesta atividade, com o próprio pensar. ${ }^{24} \mathrm{~A}$

21 MERLEAU-PONTY (op. cit., 1994) elabora o sentido do termo percepção a partir de uma critica à noção de sensação, na forma como é concebida pela tradição, visto que o "sensivel" não pode mais ser definido como o efeito imediato de um estímulo exterior (p.29), pois cada qualidade de um objeto só aparece como elemento de uma configuração (p.25); a percepção corresponde a relações e não a termos absolutos e a percepção mais elementar já está ligada a um conjunto e carregada de um sentido (p. 24 e 31). Elabora, com isso, uma critica aos limites do cientificismo: "Se nós nos reportamos às próprias investigaçōes objetivas, desccbrimos primeiramente que as condições exteriores do campo sensorial não o determinam parte por parte, e só intervêm tomando possivel uma organização autóctone - é isso que mostra a Gestatlttheorie -; em seguida, descobrimos que no organismo a estrutura depende de variáveis como o sentido biológico da situação, que não são variáveis fisicas, de forma que o conjunto (g. m.) escapa aos instrumentos conhecidos da análise fisico-matemática para abrir-se a um outro tipo de inteligibilidade. Se agora nós nos voltamos, como se faz aqui, para a experiência perceptiva, observamos que a ciência só consegue construir uma aparência de subjetividade: ela introduz sensações que são coisas ali onde a experiência mostra que já existem conjuntos significativos, ela sujeita o universo fenomenal a categorias que só são exigidas no universo da ciência. (...) A teoria da sensação, que compõe todo saber com qualidades determinadas, nos constrói objetos limpos de todo equívoco, puros, absolutos, que são antes o ideal do connecimento do que seus temas efetivos. (...) É ora a aderência do percebido a seu contexto e como que sua viscosidade, ora a presença nele de um indeterminado positivo, que impedem os conjuntos espaciais, temporais e numéricos de se articularem em termos manejáveis, distintos e identificáveis" (p. 32-34). Em O Primado da Percepçāo e suas Conseqüências Filosóficas (op. cit., 1990), MERLEAU-PONTY busca reintegrar a consciência intelectual e a consciência perceptiva, a qual seria o fundo sempre pressuposto por toda racionalidade (p. 42), estabelecendo um laço orgânica entre a percepção e a intelecção (p.55). Perguntamo-nos, assim, até que ponto a percepção, em MERLEAU-PONTY, deve ser compreendica a partir de um procedimento intelectivo e em que sentido é possivel formular um conceito de percepção.

22 Comp. FICHTE, J. G. op. cit., I, 525: "só sabes - espero eu - desse teu existir, que deve ser tomado como pressuposto, na medida em que o pensas; logo, também esse existir do eu nada mais é do que o estar-posto de ti mesmo por ti mesmo".

230 que compreendemos por pensamento se reduz apenas à consciência? ...não será também pensamento a emocionalidade, isto é, a comoção que coordena meus atos, mais alèm do autodomínio? ...não o será, também, a memória que age involuntariamente (como em Marcel PROUST)? ...não o será, também, a angústia, o desejo, a fome, a dor, o prazer do corpo?

24 Parece haver uma relação imediata com a realidade que implica na evidência da alteridade com relação ao pensar, a qual designamos por corporeidade. No entanto, não nos aparece o corpo, também ele, antes de mais nada, como pensamento? Ora, perceber o próprio corpo, seja como um todo ou uma parte do mesmo, seja em suas ações ou funções, é um modo de pensá-lo, pois ele me aparece assim no âmbito da própria atividade do meu pensar. A unidade do corpo se confunde, pois, no pensar, com o próprio pensamento, pois a atividade do pensar põe a si mesma como fundo que a tudo unifica, atuando sempre na perspectiva de compreender toda unidade como momento da sua própria unidade. Mas a circulação sangüínea, o palpitar do meu coração, a reprodução celular, todos os processos corporais não parecem me remeter, de algum modo, a algo distinto do pensar, ainda que possam ser por ele afetados? Ora, ao pensar assim em meu corpo apareço, para mim mesmo, como simultaneamente outro: meu corpo, em seu aparecer como ausência e presença ou pertença, sou eu, embora ocuito, cindindo a unidade do pensar eu-mesmo. Mas qual o sentido em estabelecer uma região da realidade, o corpo, não-passivel de ser reduzida, pelo pensar, enquanto pensa, ao próprio pensar, sendo ele, no entanto, eu-mesmo? Tal pensamento, en- 
atividade do pensar, por ser inseparável, para mim mesmo, de tudo aquilo com o qual possa se relacionar, reduz, inclui, identifica todo o pensado consigo mesma. Ora, o que poderíamos supor estar além do pensar não poderia sequer ser dito como tal sendo, da perspectiva do pensar, não-ser absoluto, assim como absoluto, para si e exclusivamente a partir de si mesmo, é o pensar. Mas se o pensar opera sempre na perspectiva de reduzir tudo a si mesmo, não restando mais nada, a questão o que é pensar? nos conduz, assim, a considerar a antípoda de sua formulação; pergunto-me, portanto, o que não é pensamento?25

Mas como compreender a alteridade do pensar a partir, exclusivamente, do pensar, ou seja, como instaurar o sentido de uma conexão entre o ser-do-pensar e o pensar o ser como alteridade, o qual equivale, de uma perspectiva exclusiva do pensar, ao nada-do-pensar, ao não-ser absoluto, como tal impensável?

A vertigem a que somos submetidos ao pretendermos expressar a própria formulação do problema deve-se, contudo, à estrutura mesma do problema, cujo lógos originário remonta a Parmênides. ${ }^{26}$

camado, enquanto envolvido em seu próprio ato de pensar, não o vê, não o percebe, no entanto, 0 corpo, senão como eu-mesmo. Mas o pensamento, encarnado, parece indicar um eu-mesmo situado na alteridade, visto que a corporeidade instaura um sentido radical à finitude. Será, pois, a morte, a estabelecer, em definitivo, que o pensamento é situado no mundo? Mas há sentido em afirmar que a finitude, a morte, nos apareça como o não-pensar, o fim, o nada do pensar, e em compreendê-la no principio da alteridade do pensar? Ora, morte e pensamento ou se excluem absolutamente (parafraseando Epicuro) ou se incluem no pensamento da imortalidade, a qual, como operar negativo, reduz à nada a própria finitude. Ou talvez, ao que tudo indica, a perspectiva ínicial resulte em uma aporia fundamental... o que torna impossível dizer que o pensamento pensa a alteridade de si mesmo e devêssemos reaprender o sentido de um conhecimento que opera em silêncio de palavras.

A formulação o que não é pensar? recairia em circularidade vazia. A passagem à formulação o que näo é pensamento? inclui, no entanto, uma substantivação prefigurada no passo anterior.

26 “Tó gar autó noeín estín te kai eínai. C'est en effet une seule et même chose que l'on pense at qui est. For there is the same thing for being thought and for being". Fr. III Clemente de Alexandria, Stromateis VI, II 23.3 (II 440.12 éd Stählin) In AUBENQUE, P. (Dir.) et alii. Études sur Parménide. Vol.1, Paris: Vrin, 1987, p. 19-20. Esta tradução considera os dois verbos no infinitivo (noeín, einai) como complementos do pronome (tó...autó), admitindo a tradução por um passivo. Para Plotino (Enéadas V 1 [10] 8.17; V 9 [5] 5.29-30 Cf. I 4 [46] 10.6; II 8 [30] 8.8; VI 7 [38] 41.18): tautón esti tó noein kai tó einai. Penser et être, c'est la même chose. Há outras propostas de traduçăo, mas o texto é considerado autêntico e se discute sobre uma base comum, ou seja, da relação entre ser e pensar. O fragmento 3, apresentado ao início, está diretamente relacionado com o fragmentos 6.1 : Khrê tó légein tó noein t'eón émenai; e 8.34: tautón d'estí voeín te kai oúneken ésti nóêma, os quais, na tradução de Charles H. KAHN (Rewiew of metaphysics 22 (1968/1969) 721-722 In op. cit., 1987, p. 210), expressam uma identidade entre o pensamento e a existência (6.1: "Cognition and statement must be what-is (i.e., must be true and real)"; 8.34: "Knowing and the goal [or aim or motive] of knowledge are the same". As controvérsias sobre a traduçăo do Poema são inúmeras, mas classificáveis em três tipos principais: 1)O problema da fixação do texto; 2)das múltiplas possibilidades de interpretação da estrutura sintática do mesmo e 3)do sentido a conferir ao verbo grego ser em todas as suas derivações. Ouanto ao primeiro problema, observe-se a revisão critica do texto fixado por DIEL-KRANZ, com base no estudo dos manuscritos, realizada por Néstor-Luis CORDERO (In AUBENOUE, P. (Dir.) et alii. Études sur Parménide. Vol. 2, Paris: Vrin, 1987, p. 324). Quanto ao segundo ponto, uma exegese da história da tradução do Poema, embora possa fornecer elementos críticos, deve resultar, no entanto, em mais uma estrutura plausível de interpretação do mesmo. Quanto ao terceiro, Charles H. KAHN (Sobre o Verbo Grego Ser e o Conceito de Ser, RJ: NEFA, 1997), observa que o verbo grego ser, em Parmênides, tem primordialmente um valor veritativo e/ou predicativo. $O$ valor existencial é derivado e deve indicar preferencialmente a existência de algo, afora outros usos do verbo, que indicam modalidades de existência, e não o 
A estrutura do problema exposto acima está delimitada pela própria condição inicial de sua formulação: a de nos situiarmos exclusivamente como observadores internos de nossos próprios pensamentos. Isso nos conduz a um paradoxo, ${ }^{27} \mathrm{o}$ qual expressa uma circularidade vazia, pois fechada em si mesma: dada a perspectiva inicial, toda outra perspectiva é negada, o que nos impossibilita expressar o próprio problema; ao dizer que o pensamento é, é vedado dizer o que não-é, é necessário dizer apenas o que é, que o pensamento é e, fora de tal tautologia inicial, nada mais pode ser dito; ao tornar "impensável", "incognoscivel", toda outra perspectiva, exclui toda perspectivação tornando-se absoluta a relação entre ser e pensar. E, no âmbito exclusivo de tal perspectiva, faz-se desnecessário dizer mais nada além de o ser é, para além do tempo, para além da individualidade, para além de toda relação: assim, o silêncio jaz na solidão...

Reitegremo-nos, pois, à postura inicial de nossa reflexão para, a partir desta, considerar a dimensão performativo-existencial inerente à tal estrutura de problematização. ${ }^{28}$ Considerando tal dimensão, a estrutura do problema nos indica, aberta, uma primeira circularidade: a de um dizer que retroage sobre o próprio dizer, delimitanto, com isso, as condições de sua validação. Mas o dizer é dizer de (alguém), distinto do sujeito gramatical, o qual só pode ser reintegrado ao dizer impessoal e absoluto - à base do não-dito. E o silêncio nos remete à segunda circularidade: a de um pensar para o qual todo o pensado neste se inclui. Mas o pensar é pensar de, oculto no aparecer do pensar, e só reintegrado à base do nãopensado. E este silêncio, ainda mais profundo, nos remete à terceira circularidade:

existir pura e simplesmente, salvo conjeturas de tradução as quais não podem prescindir de pressuposições quanto ao próprio conteúdo filosófico do texto. O valor existencial do verbo, no entanto, tem um papel fundamental na sua tese ontológica (op. cit., p. 209). O que interessa, no entanto, no contexto de nossa argumentação, é observar que em Parmênides estão estabelecidas as bases de um complexo problema que envolve duas relações principais: a relação entre ser e pensar e entre verdade e opinião (vide COLOUBARITSIS, L. op. cit. V. 2, p. 25 ) de cuja própria formulação se ocuparão os filósofos por mais de dois milênios.

27 A estrutura circular de reflexão toma-se paradoxal apenas se considerarmos o problema a partir de sua dimensão performativo-existencial, para a qual o pensar é ação que exige, além de um complemento da ação verbal (pensar em), um complemento de origem: o pensar é pensar de (alguém). Ora: 1) a redução do pensado ao próprio pensar inclui a relacionalidade na absolutidade, na identidade tautológica vazia entre ser e pensar; 2) do mesmo modo, toda alteridade em relação com o pensar, de uma perspectiva exclusiva do pensar, é nada-do-pensar, negação absoluta do pensar. Dada a perspectiva inicial, que delimita nossa atitude no sentido em que observamos o processo do pensar em ato, como observadores internos, é necessário que o pensar surja como atemporail, uno e impessoal, negando o próprio individuo pensante e, com isso, dada a consideração inicial, nega a si mesmo. A Filosofia, no decorrer de sua história, deparou-se inúmeras vezes com estruturas análogas de reflexão, no contexto de diversas concepções, aparentemente sem se dar conta de que deveria defrontar-se exatamente com a sua dimensão performativo-existencial. Mas o idealismo transcendental, exatamente por situar-se no âmbito exclusivo de tal perspectiva, não necessita reconhecer como válido nada além da perspectiva prefigurada, como estabelecemos, a seguir, no texto. Com isso, contudo, deveria calar após dizer, de uma vez por todas, o lógos que está no princípio: o ser é. A delimitação do sentido da conexão entre lógica e pensamento, a nossa condição de observadores sempre parciais em todo processo cognitivo, a consideração da dimensão biológica e corpórea como constitutivas do humano, dentre outras questōes, estão a apontar outro caminho. Outro, mas que se ergue, historicamente, sobre este apontado.

28 PLATÃO, no Eutidemo (284a, 286d, 303b), explorou, de modo privilegiado, tal condição paradoxal inerente à formulação eleática do problema, sendo conduzido à considerar o caráter performativo do mesmo. 
a do ser, para o qual o não-ser não é, só obtendo valor existencial absoluto (ser, e não ser-algo) ao incluir aquele para quem o ser é como exclusão de tudo o mais. E, assim, a exclusão opera sobre a própria individualidade, que só pode ser reintegrada à base da inversão da posição primeira do ser, no ser-algo para: e o silêncio abre-se à perspectiva da presença...

Somente a partir de tal perspectiva podemos considerar o sentido mesmo do aparecer, o qual sustenta-se sobre o fundo de um ocultar primordial, ${ }^{29}$ indicando um movimento do conhecimento do conhecimento que o situa originariamente na alteridade do mundo.

O pensamento aparece a si mesmo. O pensamento, assim, oculta-se de si mesmo. O pensamento só aparece enquanto se oculta de si mesmo, e a condição do seu aparecer é o seu ocultar e a do seu ocultar o seu aparecer. O pensamento só é, pois, enquanto revela a ausência do outro de si, a partir, exclusivamente, do aparecer como presença de si para si mesmo. O pensamento, enquanto é pura presença $\mathrm{a}^{30} \mathrm{em}$ seu aparecer para si, revela o outro a si.

29 O termo alétheia, o qual traduzimos por verdade se constrói sobre a raiz do verbo lanthánein (estar oculto e, na voz média e no aoristo, esquecer), que forma também o nome léthê (esquecimento).

30 Pretendo, neste passo, manter o sentido ambíguo de presença, como presença para si e presença para outro. 